\title{
Impact of mesenchymal stem cells derived conditioned media on neural progenitor cells
}

\author{
Filip Humenik ${ }^{1}$, Sonja Jego ${ }^{1}$, Lubica Hornakova ${ }^{2}$, Marcela Maloveska ${ }^{1}$, Alexandra Valencakova- \\ Agyagosova ${ }^{2}, Z^{1}$ uzana Vikartovska ${ }^{1,2}$, Dagmar Mudronova ${ }^{3}$, Nikola Hudakova ${ }^{1}$, Monika Zilkova $^{4}$, \\ Milan Cizek $^{1}$ and Dasa Cizkova ${ }^{1,4}$ (C) \\ ${ }^{1}$ Centre for Experimental and Clinical Regenerative Medicine, University of Veterinary Medicine and Pharmacy in Kosice, \\ Kosice, Slovakia \\ ${ }^{2}$ University Veterinary Hospital, University of Veterinary Medicine and Pharmacy in Kosice, Kosice, Slovakia \\ ${ }^{3}$ Department of Microbiology and Immunology, University of Veterinary Medicine and Pharmacy in Kosice, Kosice, Slovakia \\ ${ }^{4}$ Institute of Neuroimmunology, Slovak Academy of Sciences, Bratislava, Slovakia
}

\begin{abstract}
Neurodegenerative diseases are common problem for companion animals. Due to the limited ability of injured axons to regenerate, innovative therapies combined with rehabilitation have been applied and evaluated. Among them, stem cells and their conditioned media implantation, which can ameliorate damaged tissue has been suggested as a promising treatment strategy. The main goal of our study was to characterize mesenchymal stem cells (MSC) derived from canine adipose tissue (AT-MSC) and umbilical cord (UC-MSC) and analyse effect of their conditioned media (CM) on neurite outgrowth of neural progenitor cells isolated from the brain cortex of neonatal rats. MSC from both sources showed high osteogenic and chondrogenic potential and expression of CD90 and CD29. Furthermore, both UC-MSCCM and AT-MSCCM stimulated neurite growth. Interestingly, this effect was more pronounced with UC-MSCCM when compared to AT-MSCCM in vitro, which may be related to the different content of neurotrophic factors included in the CM.
\end{abstract}

Key words: Neural progenitor cells — Mesenchymal stem cells — Umbilical cord — Adipose tissue neurite growth

\section{Introduction}

Neural progenitor cells (NPCs) are multipotent cells that are able to generate four major cell types of the central nevous system (CNS): astrocytes, oligodendrocytes, microglia and neurons. NPCs are characterized by multilineage potency and self-renewal capacity during embryonic development and they can be found also in neurogenic regions of the adult CNS (Altman and Das 1965). In addition, the adult spinal

Correspondence to: Dasa Cizkova, Centre for Experimental and Clinical Regenerative Medicine, University of Veterinary Medicine and Pharmacy in Kosice, Kosice, Slovakia

E-mail: cizkova.dasa@gmail.com cord has been shown to contain NPCs in the white matter parenchyma (Horner et al. 2000; Yamamoto et al. 2001) and in the region around the central canal (Kulbatski and Tator 2009), either in the ependyma (Meletis et al. 2008) or subependymally (Martens et al. 2002).

Mesenchymal stem cells (MSC) are a subset of stromal cells that maintain the same fibroblast-like morphology and specific cluster of differentiation (CD) marker expression; however they also have the potential for self-renewal and ability to differentiate into adipocytes, chondrocytes, and osteoblasts in vitro (Horwitz et al. 2005). Cultured cells can be classified as MSC if they show: (1) adherence to plastic under culture conditions, (2) expression of CD105, CD73, and CD90, (3) lack of expression of CD45, CD34, CD14/

(c) The Authors 2021. This is an open access article under the terms of the Creative Commons Attribution-NonCommercial 4.0 International License (https://creativecommons.org/licenses/by-nc/4.0/), which permits non-commercial use, distribution, and reproduction in any medium, provided the original work is properly cited. 
CD11b, CD79/CD19, and HLA-DR surface markers, and (4) multilineage potential (Dominici et al. 2006). Compelling evidence exists that non-haematopoietic stem cells, including MSC, exert a substantial beneficial and therapeutic effect after transplantation in experimental CNS disease models through the secretion of immune-modulatory or neurotrophic paracrine factors (Hofer and Tuan 2016).

The stem cell-derived secreted factors including cytokines, chemokines and growth factors have gained increasing attention in recent years because of their multiple implications for the repair, restoration or regeneration of injured tissues (Kang et al. 2014). The secreted factors can be found in the medium in which the stem cells are cultured; referred as conditioned medium (CM).

The use of CM has several advantages compared to the use of stem cells, since CM can be manufactured, freeze-dried, packaged, and transported more easily. Moreover, as it is devoid of cells there is no need to match the donor and the recipient to avoid rejection (Pawitan 2014). CM released by cells contain a range of membrane-enclosed extracellular vesicles (EV). Among them, exosomes and microvesicles carry proteins, signaling lipids, and nucleic acids (mRNA, miRNA) from donor cells to recipient cells, and thus have been proposed to serve as intercellular mediators of communication (Deng et al. 2018). Especially exosomes, membrane-enclosed nanovesicles of 30 to $150 \mathrm{~nm}$ that shuttle active cargoes between different cells have received a lot of attention. Exosomes, contrary to microvesicles, are formed within multivesicular bodies (MVB) at the endolysosomal pathway and are secreted upon fusion of MVB with the plasma membrane (Kalani et al. 2014).

The aim of our study was to isolate and characterize MSC derived from umbilical cord (UC-MSC) and adipose tissue (AT-MSC), from a morphological point of view, multilineage potential and expression of CD markers (CD29, CD90, CD45) according to the criteria of International Society for Stem Cells Research (ISSCR) for MSC. Subsequently, we prepared conditioned medium from both populations of MSC and compared their impact on neurite outgrowth of NPCs.

\section{Material and Methods}

\section{Animals}

The study was performed with approval and in accordance to the guidelines of the Institutional Animal Care and Use Committee of the Slovak Academy of Sciences and with the European Communities Council Directive (2010/63/EU) regarding the use of animals in research, Slovak Law for Animal Protection No. 377/2012 and 436/2012 and protocol approval Ro-4081/17-221.

Subcutaneous fat was obtained under local anesthesia (Lidocain 2\% a.u.v, Biopharm, Czech Republic) from dor- sal scapular region of thoroughbred dogs $(n=3)$; German Shepherd (3 years old, $36 \mathrm{~kg}$ ), Royal Poodle (3 years old, $29 \mathrm{~kg}$ ) and Slovak Čuvač (4 years old, $45 \mathrm{~kg}$ ).

Umbilical cord was obtained via caesarean section (CS) under general anesthesia (Sevohale 100\% v/v, Chanele Pharmaceuticals Manufacturing, Ireland), $(n=2)$ from newborns of German Rotweiler (weight of a newborn was approximately $455 \mathrm{~g}$, number of puppies following CS was 2) and German Doberman (weight of a newborn was approximately $370 \mathrm{~g}, n=6$ ).

All these procedures were practised after clinical examination and obtaining the informed consent from their owners.

\section{Isolation, cultivation of MSC and preparation of conditioned media}

\section{AT-MSC, UC-MSC isolation procedure}

The adipose tissue (5-7 g) and umbilical cord (4-6 g), $(n=3)$ were washed extensively with phosphate buffer saline (PBS) with $2 \%$ antibiotic-antimycotic solution containing penicillin, streptomycin, and amphotericin B (Biowest, USA). Mechanically dissected tissue was then enzymatically dissociated with $0.05 \%$ Collagenase type I (Gibco, USA) under gentle agitation for $30-45 \mathrm{~min}$ at $37^{\circ} \mathrm{C}$. After incubation, digested tissue was filtered (suspension was passed through a $100-\mu \mathrm{m}$ cell strainer) to remove the rest of tissue fragments. Obtained fractions of MSC from both sources were centrifuged at $400 \times g / 10 \mathrm{~min}$. The pellets of stromal vascular fraction (SVF) and pellets which contained isolated MSC from umbilical cord were resuspended in alpha MEM medium (Biowest, USA) supplemented with 10\% fetal bovine serum (FBS) (Biowest, USA) and 1\% antibiotics (penicillin/streptomycin, Biowest, USA), and plated on $25 \mathrm{~cm}^{2}$ tissue culture flask. Non-adherent cells were removed after 2-3 days; culture media was changed twice a week.

\section{Flow cytometry with canine CD markers}

Canine AT-MSC and UC-MSC from passage 3 were sampled to investigate presence of the CD29 and CD90-positive and CD45-negative cells. Each suspension of cells $\left(1 \times 10^{6} / \mathrm{ml}\right)$ was incubated with fluorochrome-conjugated monoclonal antibodies: anti-CD45/FITC, anti-CD29/R-phycoerythrin, anti-CD90/allophycocyanin, diluted in PBS (MP Biomedicals, France) for $45 \mathrm{~min}$ at room temperature and in the dark. After incubation, the cells were washed twice with $1 \mathrm{ml}$ PBS (MP Biomedicals, France), followed by 5 min centrifugation at $250 \times g$. Finally, $100 \mu \mathrm{l}$ PBS were added and cytometric analysis was performed on a BD FACSCanto ${ }^{\mathrm{TM}}$ flow cytometer (Becton Dickinson Biosciences, USA) equipped with a blue $(488 \mathrm{~nm})$ and a red $(633 \mathrm{~nm})$ laser and six fluorescence detectors. The percentage of cells expressing the individual CD characters was determined by means of dot plotting for the 
respective fluorescence. The data obtained were analyzed in the BD FACS DivaTM analysis software. For flow cytometry, the following antibodies were employed according to the supplier's recommendations: phycoerythrin anti-human CD29/ IgG1 (Clone: TS2/16, human, canine, Sony Biotechnology); FITC anti-dog CD45/IgG2b (Clone: YKIX716.13, BIOPORT, CZ); allophycocyanin anti-dog CD90/IgG2b (Clone: YKIX337.217, BIOPORT, CZ); and their isotype controls: FITC dog IgG (CD29) and phycoerythrin, allophycocyanin dog IgG2b (CD45, CD90) from Biolegend.

\section{Three-lineage profile of AT-MSC and UC-MSC (osteogenic,} chondrogenic and adipogenic phenotypes)

The multilineage potential of canine AT-MSC and UC-MSC (passages 3) was determined by incubation with commercial StemPro Differentiation Kits containing all the reagents required for inducing canine AT-MSC and UC-MSC into chondrogenic, osteogenic, and adipogenic lineages. Cultures were stimulated with the appropriate differentiation medium for 21 days according to the recommended differentiation protocol for each specific lineage. Afterward, the cultures were fixed with $4 \%$ formaldehyde and stained with the following reagents: adipogenic culture with Oil Red, osteogenic culture with Alizarin Red S, and chondrogenic culture with Alcian Blue (all from Sigma-Aldrich, USA).

\section{Conditioned media preparation AT-derived and UC-derived} conditioned media

AT-MSCCM and UC-MSCCM at passage 3 were cultured in Dulbecco's Modified Eagle Medium (DMEM, Biowest, USA) without FBS (Biowest, USA) and antibiotics. After $24 \mathrm{~h}$ incubation in a humidified atmosphere with $5 \% \mathrm{CO}_{2}$ at $37^{\circ} \mathrm{C}$, collected media samples were centrifuged at $400 \times g$ for $10 \mathrm{~min}$ to remove cell debris, and filtered through a $0.2 \mu \mathrm{m}$ sterile syringe filter (Millipore, USA). We have used identical procedure as published recently (Humenik et al. 2019). After obtaining conditioned media from both sources, the protein concentration of the CM was quantified by Bradford protein assay, using standard Bradford reagent (Sigma), to ensure that equal concentrations $(1.0 \mathrm{mg} / \mathrm{ml})$ of $\mathrm{CM}$ were used. DMEM was regarded as a control (nonconditioned medium). Samples of AT-MSCCM and UC-MSCCM were collected and stored at $-80^{\circ} \mathrm{C}$ until the time of use.

\section{Primary culture of brain cortex NPCs}

NPCs were isolated from the brain cortex of three days old neonatal Wistar rats $(n=3)$. Animals were anesthetised on ice and afterwards sacrificed by decapitation. The entire brain cortex was removed, meninges were dissected away and brain cortex tissue was minced with sterile microsurgi- cal scissors into small pieces and mechanically dissociated. Cell suspension was centrifuged $8 \mathrm{~min}$ at $400 \times \mathrm{g}$. Cells were plated in 6 well plates $\left(3 \times 10^{5}\right.$ cells per well) and in 24 well plates $\left(15 \times 10^{3}\right.$ cells per well) grown in complete proliferative culture media (CPCM) composed of DMEM and Ham's F12 (DMEM-F12, Biosera, Philipines) supplemented with $5 \mathrm{mg} / \mathrm{ml}$ streptomycin, $5 \mathrm{IU} / \mathrm{ml}$ penicillin (Biochrom, UK), B27 (10 ng/ml), N2 (10 ng/ml) (Gibco, USA), bFGF (basic fibroblast growth factor) $(20 \mathrm{ng} / \mathrm{ml})$ (Milipore, USA), EGF (epidermal growth factor) $(20 \mathrm{ng} / \mathrm{ml}$ ) (AppliChem, Germany), $3 \% \mathrm{FBS}$, at $37^{\circ} \mathrm{C}$ in $5 \% \mathrm{CO}_{2}$ incubator for 4 days in vitro (DIV4).

\section{Immunohistochemistry characterization of NPCs culture}

DIV4 cells were fixed with $4 \%$ paraformaldehyde for $15 \mathrm{~min}$ and incubated with Anti-neurofilament 200 antibody (NF200, rabbit polyclonal IgG, Merck, USA) and Antiglial fibrilary acidic protein (GFAP, rabbit polyclonal; Dako, USA). Appropriate secondary antibodies FITC (green goat anti-rabbit, Molecular probes, USA) were used. The cells were counterstained with 4,6-diamidino-2-phenylindole (DAPI, Sigma, USA) to reveal nuclei. The staining was detected by fluorescent microscopy (Zeiss, Germany) and pictures were taken by microscope camera (Zeiss Axiocam ERc 5s, Zeiss, Germany).

\section{Quantification of neurite outgrowth}

After 4 days, when primary culture of NPCs revealed typical neurosphere-like structures and reached 60-70\% sub-confluence, cells were treated with $0.25 \%$ trypsin, and replated in 24-well plates $\left(15 \times 10^{3}\right.$ cells per well) for neurite growth.

NPCs were cultivated in DMEM with 5\% FBS and 1\% ATB for 2 days in order to adhere to plastic. Afterwards the medium was replaced to: i) AT-MSCCM $(n=3)$, ii) UC-MSCCM $(n=3)$, iii) negative CTR (control) medium (DMEM no supplements, $n=3$ ) and iv) positive CTR (DMEM supplemented with B27 (10 ng/ml), $n=3)$, N2 (10 ng/ml), recombinant human bFGF $(20 \mathrm{ng} / \mathrm{ml})$ and human EGF $(20 \mathrm{ng} / \mathrm{ml})$ ) and cultured for three days. The number of processes was quantified in each condition at day 1 , day 2 and day 3 of culture in positive control, negative control, AT-MSCCM and UC-MSCCM using the Zeiss software (Carl Zeiss AxioVision software). The number of processes was counted in 10 different fields/per each group and then averaged using Fiji ImageJ software similar as Pemberton (Pemberton et al. 2018).

\section{Statistical analysis}

All the data are presented as mean \pm standard deviation. Comparisons among multiple groups (negative control, 

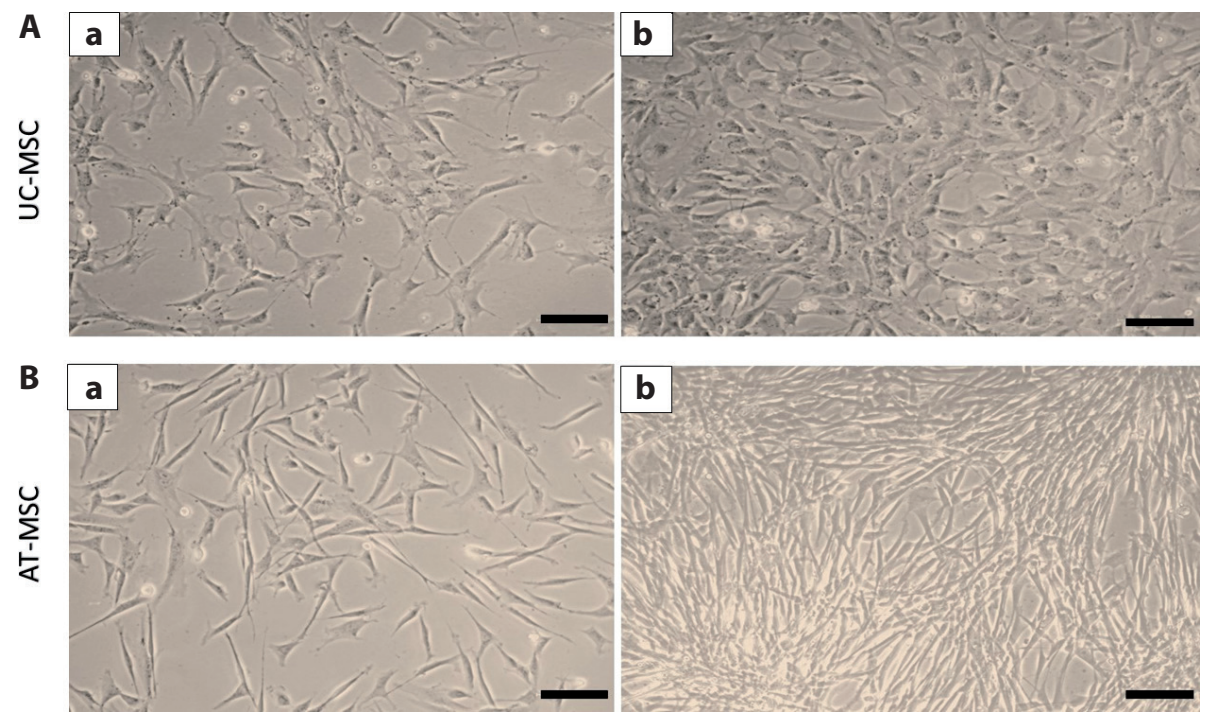

Figure 1. Morphological comparison of UC-MSC (umbilical cord mesenchymal stem cells; A) and AT-MSC (adipose tissue mesenchymal stem cells; B). UC-MSC: passage 3, day in vitro 6 (DIV6) (a); passage 3, DIV10 (b). AT-MSC: passage 3, DIV3 (a); passage 3, DIV7 (b). Scale bars: $50 \mu \mathrm{m}$.
UCMSC-CM and ATMSC-CM) were performed by Oneway ANOVA for each day using GraphPad Prism 5.0 (GraphPad Software, Inc, San Diego, CA). Significance was set as follows: ${ }^{\star} p<0.05, p<0.01$ and ${ }^{* *} p<0.001$.

\section{Results}

\section{Morphologic characteristics}

Using above-mentioned protocols, we were able to isolate MSC from adipose tissue and umbilical cord. Morphological comparison of UC-MSC and AT-MSC showed some typical features for each population, while UC-MSC showed fibroblast-like shape (Fig. 1A), the AT-MSC revealed spindlelike shape (Fig. 1B).

\section{Flow cytometry profile}

Flow cytometry analyses of AT-MSC and UC-MSC from third passage showed that both cell populations expressed CD markers typical for MSC. AT-MSC expressed primarily CD29 (99.4\%) and CD90 (78.6\%) but low CD45 (1.3\%), while UC-MSC from identical passage showed higher expression of CD45 (11.6\%), CD29 (98.4\%) and reduced CD90 (46.2\%) in comparison with AT-MSC (Fig. 2).

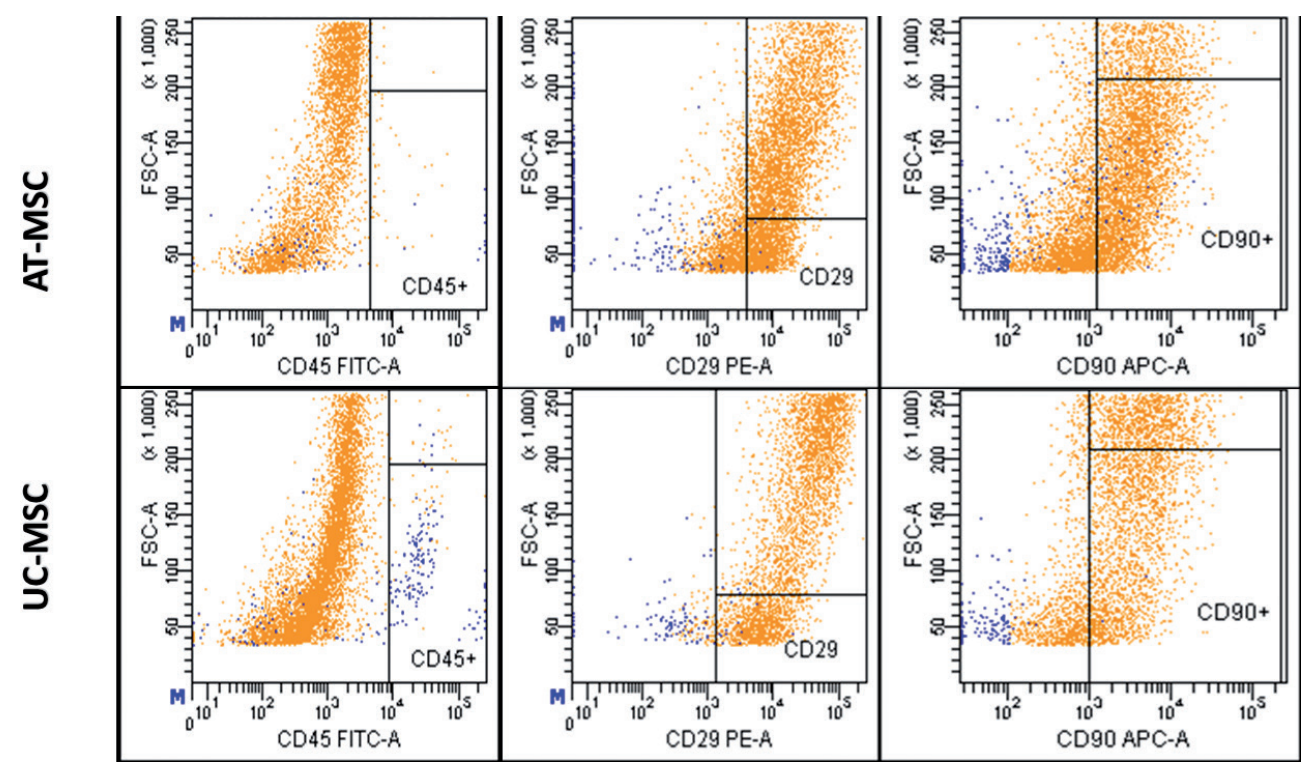

Figure 2. Representative flow cytometry analyses with canine $\mathrm{CD}$ markers of AT-MSC CD45 (1.3\%), CD29 (99.4\%) and CD90 (78.6\%) (upper panel) and UC-MSC CD45 (11.6\%), CD29 (98.4\%) and CD90 (46.2\%) (lower panel) from passage 3 presented as scatter blot. 

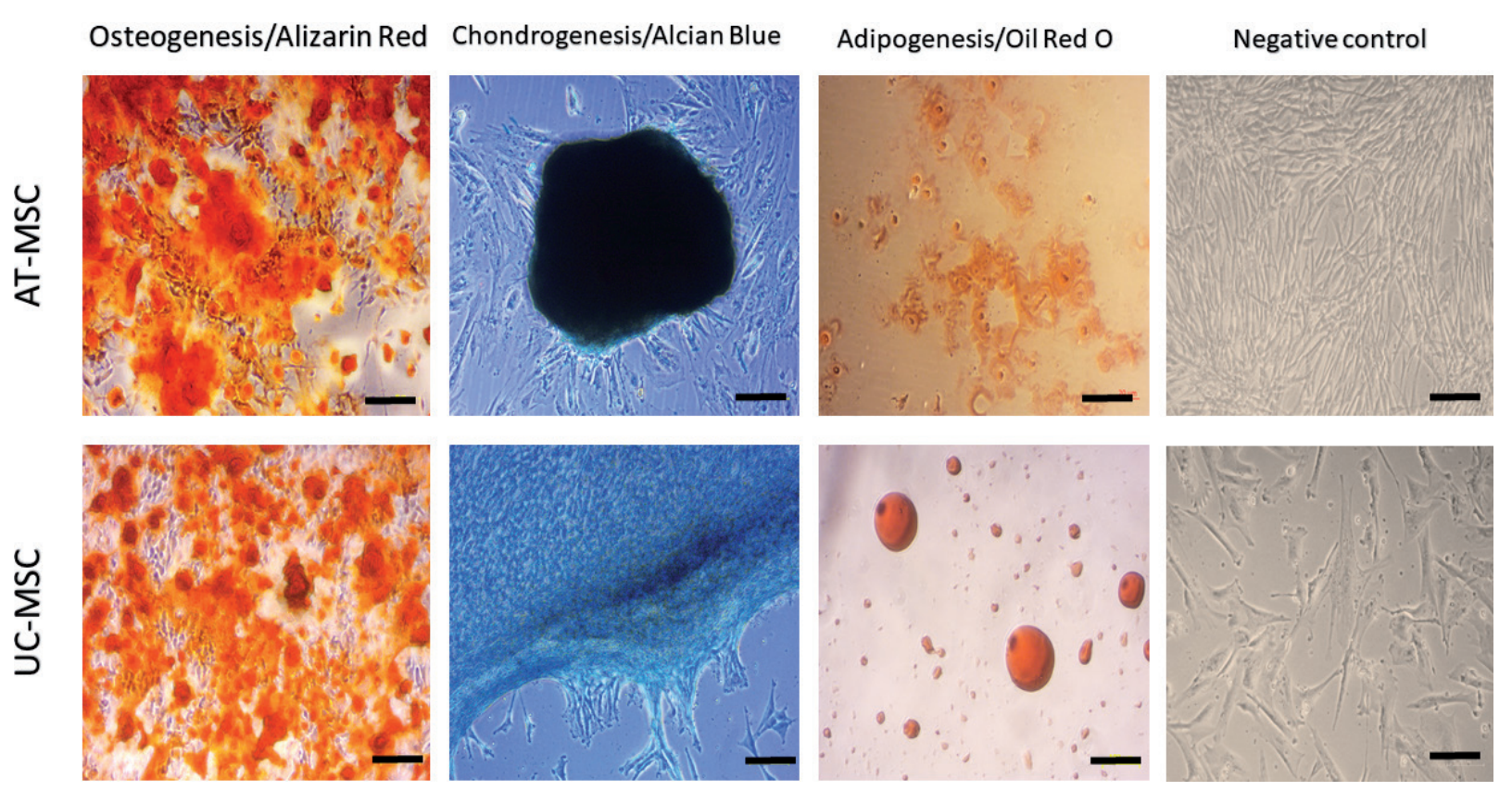

Figure 3. Multilineage differentiation of AT-MSC (upper panel) and UC-MSC (lower panel). Figures represent multilineage potential of canine MSC isolated from adipose tissue and umbilical cord, differentiated into osteocytes (Alizarin Red), chondrocytes (Alcian Blue) and adipocytes (Oil Red O). Scale bar $50 \mu \mathrm{m}$.

\section{Multilineage potential}

Three-lineage potential was detected by using commercial StemPro ${ }^{\circledast}$ Differentiation Kits. Present data confirmed that canine AT-MSC and UC-MSC after 21 days of incubation in specific differentiation medium underwent a high degree of biomineralizing osteogenesis. This was confirmed by Alizarin Red S which is an anthraquinone dye used to stain calcium deposites. Similarly, we captured a significant chondrogenic potential. In addition, chondrocytes migrating from spherical chondrocyte-like aggregates revealed intense Alcian Blue staining, which is typical for chondrogenesis. On the contrary, we found a low degree of adipogenesis, with limited vacuole formation and Oil Red staining (Fig. 3).

\section{Immunohistochemistry characterization of NPCs culture}

For NPCs characterization, we used NF200 and GFAP antibody. NF200 is widely accepted as marker for large myelinated A- $\beta$ fibers of neurons, while GFAP is expressed by astrocytes and ependymal cells. Population of NPCs was
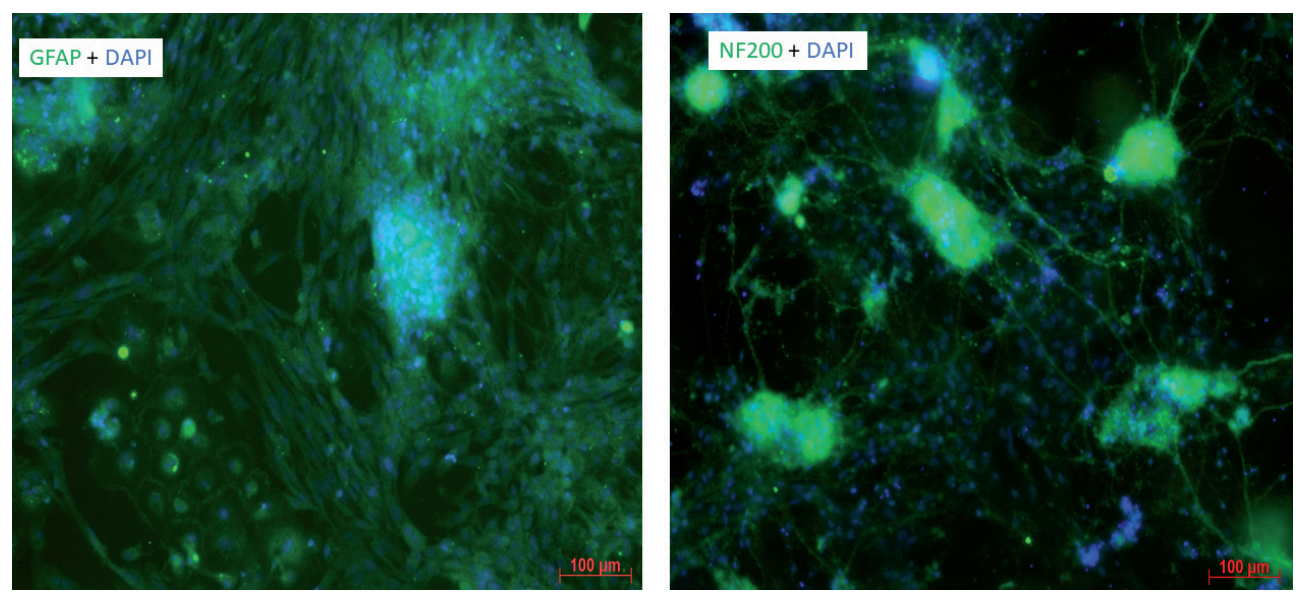

Figure 4. The expression of glial (GFAP) and neural (NF200) markers. The cells were counterstained with 4,6-diamidino-2-phenylindole (DAPI) detected by fluorescent microscopy. Scale bar $100 \mu \mathrm{m}$. 
positive for both markers (Fig. 4). Furthermore, we observed formation of neurosphere-like structures of various diameters, which disintegrate spontaneously and formed connected networks of neural cells populations after further in vitro culture conditions.

\section{Neurite outgrowth}

Bradford measurement as quantitative method for analyses of conditioned media from both sources showed only mild differences between concentrations of proteins in UC-MSCCM and AT-MSCCM (1.40 mg/ml and $1.17 \mathrm{mg} /$ $\mathrm{ml}$ proteins, respectively). Thus, both $\mathrm{CM}$ were diluted to final concentration of $1.0 \mathrm{mg} / \mathrm{ml}$ for neurite outgrowth experiment.

In vitro study confirmed neurotrophic-like stimulatory properties of UC-MSCCM and AT-MSCCM with promoted neurite outgrowth. Positive control medium, containing high concentration of neurotrophic factors, showed the most significant effect (Fig. 5) on the number of neurite processes from day 1 to day 3 (91.98\% increase of number of processes compared to the negative control over 3 days of cultivation) (Fig. 6). However, the concentration of the neurotrophic factors in CM of positive control (Positive CTR) was significantly above the physiological range therefore, we did not compare these data with both experimental groups (UC-MSCCM and AT-MSCCM). Furthermore, UC-MSCCM showed a significant increase of number of processes compared to the negative control at day $2(p<$ $0.01)$ and day $3(p<0.01)$ but not at day 1 , although data were close from reaching significant results $(p=0.0709)$.

Similarly, AT-MSCCM showed a significant enhancement of processes outgrowth compared to the negative control at day $1(p<0.05)$ but not the following days (day 2: $p=0.5689$; day $3: p=0.69)$.

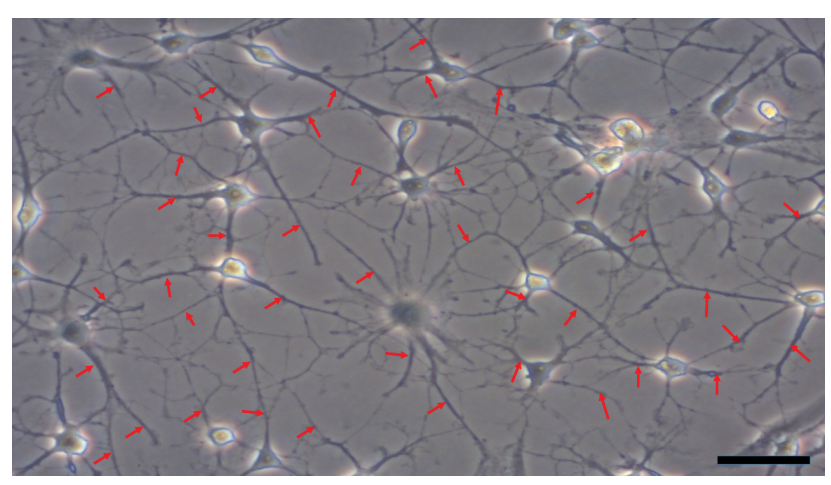

Figure 5. Analysis of neurite growth. The average number of processes was measured using Zeiss's software. An arrow (in red) was placed on each of the neurite in each field, excluding those that are not completely in the field. Scale bar $50 \mu \mathrm{m}$. (For color figure see online version of the manuscript).

\section{Discussion}

Several adult tissues have been identified as potential sources of MSC including bone marrow, adipose tissue, placenta, umbilical cord, umbilical cord blood, amnion, dental pulp, liver parenchyma and many others (Berebichez-Fridman and Montero-Olvera 2018; Humenik et al. 2019; Kholodenko et al. 2019). In order to isolate MSC from adipose tissue and umbilical cord, we used a combined method of mechanical disruption and enzymatic digestion with the enzyme collagenase I or IV (Buyl et al. 2015; Mastrolia et al. 2019). The enzymatic process lasted 25-45 $\mathrm{min}$, depending on the amount and structure of the digested fraction. However, prolonged digestion could damage cells, because of cells sensibility to proteolytic enzymes (Mushahary et al. 2018; Mastrolia et al. 2019).

Isolated MSC revealed differences in several parameters, similarly as reported in previous experiments (BerebichezFridman and Montero-Olvera 2018). MSC derived from adipose tissue showed a spindle shape and 100-140 $\mu \mathrm{m}$ in perimeter. On the other hand, MSC isolated from umbilical cord showed fibroblast-like shape and cells were significantly smaller, ranging around $80 \mu \mathrm{m}$.

Interesting data were obtained while monitoring the multidifferentiation capacity of isolated cell populations. Cells from each population were tested for their capacity to differentiate into osteogenic, chondrogenic and adipogenic line. MSC isolated from both sources, adipose tissue and umbilical cord, showed a very good ability to differentiate into osteogenic and chondrogenic line, but very little or no ability to differentiate towards adipogenic cells, even after repeating the experiment several times. This inability of MSC adipogenesis has been described also in other studies (Kern et al. 2006; Kozlowska et al. 2019). A key role in this phenomenon may play up regulation of bioactive molecules such as: Runx2, Wnt10b, RhoA, which are capable of mediating osteogenesis but suppressing adipogenesis (Zhang et al. 2012).

Flow cytometry of CD surface markers expression outlined few variations as well. AT-MSC from the third passage showed low expression of CD45+ cells and high expression of the CD 29+ and CD90+ cells. On the contrary, UC-MSC from the same passage showed higher expression of CD45+ and less expression of CD90+ cells while slight difference was detected for CD29+. From flow cytometry results, we can conclude that each cell population is unique and homogeneity can be achieved by passaging or modifying isolation technique. It should be noted that the actual expression of positive and negative markers also depends on the source from which the MSC were isolated (Maleki et al. 2014) as well as on the age of donors (Lin et al. 2013) and the cellular aging (replicative capabilities) (Yang et al. 2018). In addition, slight differences may occure even between individual samples.

It is well documented that MSC are stimulating the environment and other cells through the paracrine activ- 
A

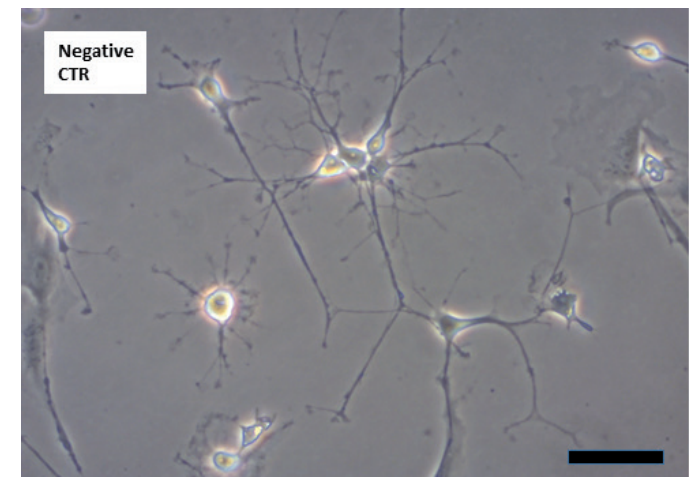

C

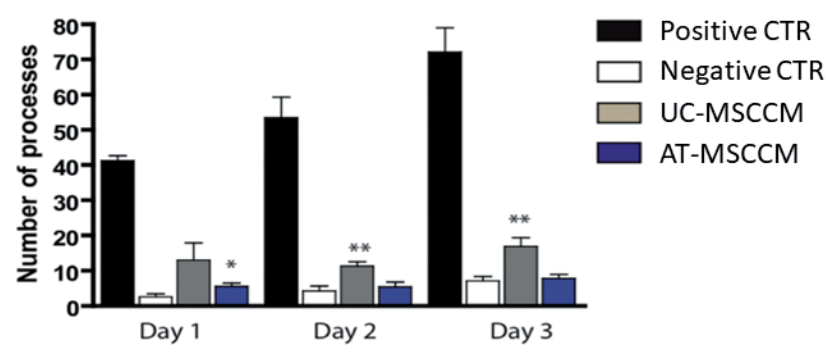

B

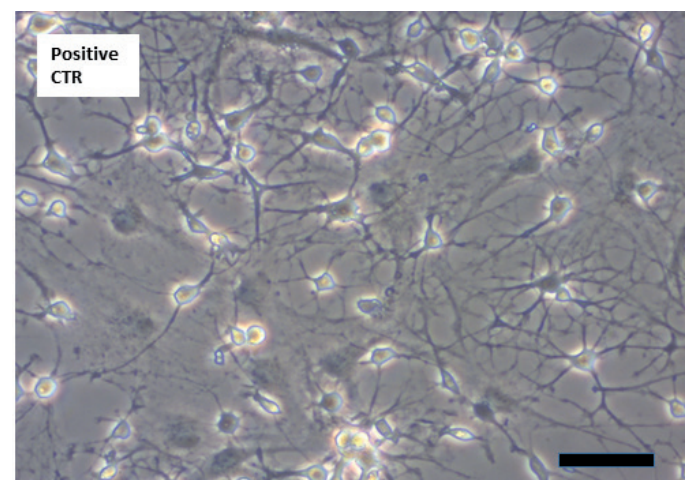

Figure 6. Neurotrophic potential of Positive CTR and Negative CTR on neurite outgrowth. Brightfield images illustrating the number of processes in Negative CTR (DMEM, no supplement) (A) and Positive CTR (DMEM supplemented with B27, N2, recombinant human bFGF and human EGF) (B). Scale bar $50 \mu \mathrm{m}$. Bar graph evaluating neurotrophic potential of umbilical cord mesenchymal stem cells conditioned medium (UC-MSCCM, grey bars) and adipose tissue mesenchymal stem cells medium (ATMSCCM, blue bars) compared to Positive CTR (black bars) and Negative CTR (white bars) on neurite outgrowth of NPCs primary culture during 3 days of cultivation (C). Data represent mean value \pm SEM. Unpaired t-test between the UC-MSCCM or AT-MSCCM and negative control conditions within the same day ${ }^{\star} p<0.05$ and ${ }^{\star *} p<0.01$.

ity via production of growth factors, mediators and other bioactive molecules, included in a conditioned medium (Humenik et al. 2019; Rezaie et al. 2019; Maacha et al. 2020). Previous study focused on proteomic analyses of MSCCM from adipose tissue and umbilical cord showed, that there are differences in composition of secretomes from these sources (Shin et al. 2021). However, according to previous studies, the gender or strain differences have no major effect on composition of CM (Barzilay et al. 2009; Teshima et al. 2019). Here, we have compared neurotrophic stimulation of two CM derived from MSC of different origin. Our findings showed that both UC-MSCCM and AT-MSCCM enhanced neurite growth. Interestingly, this effect was more pronounced with UC-MSCCM than AT-MSCCM. The accelerated neurite outgrowth can be explained by the paracrine potential of MSC mediated through increased production of HGF (hepatocyte growth factor), VEGF (vascular endothelial growth factor), IGF (insuline growth factor), EGF (epidermal growth factor), GDNF (glial cell-line derived neurotrophic factor), BDNF (brain-derived neurotrophic factor), NT3 (neurotrophin-3), TGF (transforming growth factor), angiopoietin, and adhesion molecules (Pawitan 2014; Dabrowski et al. 2017; Dong et al. 2018; Mukai et al. 2018; Cofano et al. 2019; Xiang et al. 2020).

These data are in line with present findings revealing neurite outgrowth, which was most likely promoted by UC-MSC- secreted BDNF and GDNF (Qi et al. 2018). Furthermore, in vitro co-cultures showed that UC-MSC promote neuronal/ glial survival and neuritogenesis also through the secretion of BDNF and $\beta$-NGF (Pawitan et al. 2017). Characterization of UC-MSCCM by antibody-based protein array analyses and by enzyme-linked immunosorbent assays (ELISA) showed enrichment of IGF-1, HGF, VEGF and TGF- $\beta$ (Arutyunyan et al. 2016, Ahangar et al. 2020). In addition, neuroprotective efficacy of UC-MSC and its products was confirmed also in vivo by treating cerebral palsy (Wang et al. 2015; Okur et al. 2018) or SCI (Cheng et al. 2014).

In summary, present study provides evidence that UCMSCCM has a greater effect on neurite outgrowth compared to AT-MSCCM, suggesting that UC-MSC are probably secreting more neurotrophic factors (Cofano et al. 2019). Indeed, the number of processes counted are not the only indicator of neurite growth, but also length or ramification are key parameters for neuritogenesis that need to be taken in account in the future studies.

\section{Conclusion}

In this study, we showed that CM derived from MSC of different tissue origin have a beneficial effect on neurite outgrowth. Interestingly, we found that UC-MSCCM had 
a more stimulatory effect on neurite outgrowth when compared to AT-MSCCM, which may be associated with the capacity of releasing a higher content of neurotrophic factors. These data correlate with previous study of UC-MSCCM revealing higher secretion of neurotrophic factors (bFGF, NGF, NT3, NT4, GDNF), lower immunogenicity in the host tissue, higher anti-inflammatory effect in injured nervous tissue than by AT-MSCCM (Cofano et al. 2019).

Acknowlegment. This study was supported by grants APVV-190193, VEGA 1/0376/20.

Authors contribution. DC, FH and SJ conceived of the presented idea. FH, SJ, MM, MC, and NH planned the experiments. MZ, LH, $\mathrm{AV}$-A were crucial for obtaining tissues for MSC isolation. $\mathrm{FH}, \mathrm{ZV}$ and SJ aided with cell isolation, cultivation and passaging. FH, DM performed the MSC and CM characterization. MZ, SJ, MM and FH carried out the experiments on NPC. DC, FH, SJ contributed to the interpretation of the results. All authors wrote and revised the manuscript. DC finantially supported the experiments.

\section{References}

Ahangar P, Mills SJ, Cowin AJ (2020): Mesenchymal stem cell secretome as an emerging cell-free alternative for improving wound repair. Int. J. Mol. Sci. 21, E7038 https://doi.org/10.3390/ijms21197038

Altman J, Das GD (1965): Autoradiographic and histological evidence of postnatal hippocampal neurogenesis in rats. J. Comp. Neurol. 124, 319-335 https://doi.org/10.1002/cne.901240303

Arutyunyan I, Fatkhudinov T, Kananykhina E, Usman N, Elchaninov A, Makarov A, Bolshakova G, Goldshtein D, Sukhikh G (2016): Role of VEGF-A in angiogenesis promoted by umbilical cord-derived mesenchymal stromal/stem cells: in vitro study. Stem Cell Res. Ther. 7, 46 https://doi.org/10.1186/s13287-016-0305-4

Barzilay R, Sadan O, Melamed E, Offen D (2009): Comparative characterization of bone marrow-derived mesenchymal stromal cells from four different rat strains. Cytotherapy 11, $435-442$ https://doi.org/10.1080/14653240902849796

Berebichez-Fridman R, Montero-Olvera PR (2018): Sources and clinical applications of mesenchymal stem cells: state-of-the-art review. Sultan Qaboos Univ. Med. J. 18, e264-e277 https://doi.org/10.18295/squmj.2018.18.03.002

Buyl K, Vanhaecke T, Desmae T, Lagneaux L, Rogiers V, Najar M, De Kock J (2015): Evaluation of a new standardized enzymatic isolation protocol for human umbilical cord-derived stem cells. Toxicol. In Vitro 29, 1254-1262 https://doi.org/10.1016/j.tiv.2014.12.008

Cheng H, Liu X, Hua R, Dai G, Wang X, Gao J, An Y (2014): Clinical observation of umbilical cord mesenchymal stem cell transplantation in treatment for sequelae of thoracolumbar spinal cord injury. J. Transl. Med. 12, 253 https://doi.org/10.1186/s12967-014-0253-7
Cofano F, Boido M, Monticelli M, Zenga F, Ducati A, Vercelli A, Garbossa D (2019): Mesenchymal stem cells for spinal cord injury: current options, limitations, and future of cell therapy. Int. J. Mol. Sci. 20, E2698 https://doi.org/10.3390/ijms20112698

Dabrowski FA, Burdzinska A, Kulesza A, Sladowska A, Zolocinska A, Gala K, Paczek L, Wielgos M (2017): Comparison of the paracrine activity of mesenchymal stem cells derived from human umbilical cord, amniotic membrane and adipose tissue. J. Obstet. Gynaecol. Res. 43, 1758-1768 https://doi.org/10.1111/jog.13432

Deng H, Sun C, Sun Y, Li H, Yang L, Wu D, Gao Q, Jiang X (2018): Lipid, protein, and microrna composition within mesenchymal stem cell-derived exosomes. Cell. Reprogramming 20, 178-186 https://doi.org/10.1089/cell.2017.0047

Dominici M, Le Blanc K, Mueller I, Slaper-Cortenbach I, Marini F, Krause D, Deans R, Keating A, Prockop D, Horwitz E (2006): Minimal criteria for defining multipotent mesenchymal stromal cells. The International Society for Cellular Therapy position statement. Cytotherapy 8, 315-317 https://doi.org/10.1080/14653240600855905

Dong H, Li G, Shang C, Yin H, Luo Y, Meng H, Li X, Wang Y, Lin L, Zhao M (2018): Umbilical cord mesenchymal stem cell (UC-MSC) transplantations for cerebral palsy. Am. J. Transl. Res. 10, 901-906

Hofer HR, Tuan RS (2016): Secreted trophic factors of mesenchymal stem cells support neurovascular and musculoskeletal therapies. Stem Cell Res. Ther. 7, 131 https://doi.org/10.1186/s13287-016-0394-0

Horner PJ, Power AE, Kempermann G, Kuhn HG, Palmer TD, Winkler J, Thal LJ, Gage FH (2000): Proliferation and differentiation of progenitor cells throughout the intact adult rat spinal cord. J. Neurosci. Off. J. Soc. Neurosci. 20, 2218-2228 https://doi.org/10.1523/JNEUROSCI.20-06-02218.2000

Horwitz EM, Le Blanc K, Dominici M, Mueller I, Slaper-Cortenbach I, Marini FC, Deans RJ, Krause DS, Keating A, International Society for Cellular Therapy (2005): Clarification of the nomenclature for MSC: The International Society for Cellular Therapy position statement. Cytotherapy 7, 393-395 https://doi.org/10.1080/14653240500319234

Humenik F, Cizkova D, Cikos S, Luptakova L, Madari A, Mudronova D, Kuricova M, Farbakova J, Spirkova A, Petrovova E, et al. (2019). Canine bone marrow-derived mesenchymal stem cells: genomics, proteomics and functional analyses of paracrine factors. Mol. Cell. Proteomics 18, 1824-1835 https://doi.org/10.1074/mcp.RA119.001507

Kalani A, Tyagi A, Tyagi N (2014): Exosomes: mediators of neurodegeneration, neuroprotection and therapeutics. Mol. Neurobiol. 49, 590-600 https://doi.org/10.1007/s12035-013-8544-1

Kang BJ, Kim H, Lee SK, Kim J, Shen Y, Jung S, Kang KS, Im SG, Lee SY, Choi M, et al. (2014): Umbilical-cord-blood-derived mesenchymal stem cells seeded onto fibronectin-immobilized polycaprolactone nanofiber improve cardiac function. Acta Biomater. 10, 3007-3017

https://doi.org/10.1016/j.actbio.2014.03.013

Kern S, Eichler H, Stoeve J, Klüter H, Bieback K (2006): Comparative analysis of mesenchymal stem cells from bone marrow, 
umbilical cord blood, or adipose tissue. stem cells dayt. Ohio 24, 1294-1301

https://doi.org/10.1634/stemcells.2005-0342

Kholodenko IV, Kurbatov LK, Kholodenko RV, Manukyan GV, Yarygin KN (2019): Mesenchymal stem cells in the adult human liver: hype or hope? Cells 8, E1127 https://doi.org/10.3390/cells8101127

Kozlowska U, Krawczenko A, Futoma K, Jurek T, Rorat M, Patrzalek D, Klimczak A (2019): Similarities and differences between mesenchymal stem/progenitor cells derived from various human tissues. World J. Stem Cells 11, 347-374 https://doi.org/10.4252/wjsc.v11.i6.347

Kulbatski I, Tator CH (2009): Region-specific differentiation potential of adult rat spinal cord neural stem/precursors and their plasticity in response to in vitro manipulation. J. Histochem. Cytochem. 57, 405-423 https://doi.org/10.1369/jhc.2008.951814

Lin CS, Xin ZC, Dai J, Lue TF (2013): Commonly used mesenchymal stem cell markers and tracking labels: limitations and challenges. Histol. Histopathol. 28, 1109-1116

Maacha S, Sidahmed H, Jacob S, Gentilcore G, Calzone R, Grivel JC, Cugno C (2020): Paracrine mechanisms of mesenchymal stromal cells in angiogenesis. Stem Cells Int. 2020, 1-12 https://doi.org/10.1155/2020/4356359

Maleki M, Ghanbarvand F, Reza Behvarz M, Ejtemaei M, Ghadirkhomi E (2014): Comparison of mesenchymal stem cell markers in multiple human adult stem cells. Int. J. Stem Cells 7, 118-126 https://doi.org/10.15283/ijsc.2014.7.2.118

Martens DJ, Seaberg RM, van der Kooy D (2002): In vivo infusions of exogenous growth factors into the fourth ventricle of the adult mouse brain increase the proliferation of neural progenitors around the fourth ventricle and the central canal of the spinal cord. Eur. J. Neurosci. 16, 1045-1057 https://doi.org/10.1046/j.1460-9568.2002.02181.x

Mastrolia I, Foppiani EM, Murgia A, Candini O, Samarelli A.V, Grisendi G, Veronesi E, Horwitz EM, Dominici M (2019): Challenges in clinical development of mesenchymal stromal/stem cells: concise review. Stem Cells Transl. Med. 8, $1135-1148$ https://doi.org/10.1002/sctm.19-0044

Meletis K, Barnabé-Heider F, Carlén M, Evergren E, Tomilin N, Shupliakov O, Frisén J (2008): Spinal cord injury reveals multilineage differentiation of ependymal cells. PLoS Biol. 6, e182 https://doi.org/10.1371/journal.pbio.0060182

Mukai T, Tojo A, Nagamura-Inoue T (2018): Umbilical cordderived mesenchymal stromal cells contribute to neuroprotection in neonatal cortical neurons damaged by oxygen-glucose deprivation. Front. Neurol. 9, 466 https://doi.org/10.3389/fneur.2018.00466

Mushahary D, Spittler A, Kasper C, Weber V, Charwat V (2018): Isolation, cultivation, and characterization of human mesenchymal stem cells. Cytom. Part J. Int. Soc. Anal. Cytol. 93, 19-31 https://doi.org/10.1002/cyto.a.23242

Okur SÇ, Erdoğan S, Demir CS, Günel G, Karaöz E (2018): the effect of umbilical cord-derived mesenchymal stem cell transplantation in a patient with cerebral palsy: A case report. Int. J. Stem Cells 11, 141-147 https://doi.org/10.15283/ijsc17077
Pawitan J (2014): Prospect of stem cell conditioned medium in regenerative medicine. BioMed Res. Int. 2014, 965849 https://doi.org/10.1155/2014/965849

Pawitan J, Leviana M, Sukmawati D, Liem I, Margiana R, Tarcisia T (2017): Prospect of umbilical cord mesenchymal stem cell culture waste in regenerative medicine. J. Glob. Pharma Technol. 9

Pemberton K, Mersman B, Xu F (2018): Using ImageJ to assess neurite outgrowth in mammalian cell cultures: research data quantification exercises in undergraduate neuroscience lab. J. Undergrad. Neurosci. Educ. 16, A186-A194

Qi L, Xue X, Sun J, Wu Q, Wang H, Guo Y, Sun B (2018): The promising effects of transplanted umbilical cord mesenchymal stem cells on the treatment in traumatic brain injury. J. Craniofac. Surg. 29, 1689-1692 https://doi.org/10.1097/SCS.0000000000005042

Rezaie J, Heidarzadeh M, Hassanpour M, Amini H, Shokrollahi E, Rahbarghazi R (2019): The angiogenic paracrine potential of mesenchymal stem cells. In: Mesenchymal Stem Cells. IntechOpen https://doi.org/10.5772/intechopen.84433

Shin S, Lee J, Kwon Y, Park KS, Jeong JH, Choi SJ, Bang SI, Chang JW, Lee C (2021): comparative proteomic analysis of the mesenchymal stem cells secretome from adipose, bone marrow, placenta and wharton's jelly. Int. J. Mol. Sci. 22, 845 https://doi.org/10.3390/ijms22020845

Teshima T, Matsuoka A, Shiba M, Dairaku K, Matsumoto H, Suzuki R, Koyama H (2019): Comparison of properties of stem cells isolated from adipose tissue and lipomas in dogs. Stem Cells Int. 2019, 1609876 https://doi.org/10.1155/2019/1609876

Wang X, Hu H, Hua R, Yang J, Zheng P, Niu X, Cheng H, Dai G, Liu $\mathrm{X}$, Zhang Z, et al. (2015): Effect of umbilical cord mesenchymal stromal cells on motor functions of identical twins with cerebral palsy: pilot study on the correlation of efficacy and hereditary factors. Cytotherapy 17, 224-231 https://doi.org/10.1016/j.jcyt.2014.09.010

Xiang E, Han B, Zhang Q, Rao W, Wang Z, Chang C, Zhang Y, Tu C, Li C, Wu D (2020): Human umbilical cord-derived mesenchymal stem cells prevent the progression of early diabetic nephropathy through inhibiting inflammation and fibrosis. Stem Cell Res. Ther. 11, 336 https://doi.org/10.1186/s13287-020-01852-y

Yamamoto S, Yamamoto N, Kitamura T, Nakamura K, Nakafuku M (2001): Proliferation of parenchymal neural progenitors in response to injury in the adult rat spinal cord. Exp. Neurol. 172, 115-127 https://doi.org/10.1006/exnr.2001.7798

Yang YHK, Ogando CR, Wang See C, Chang TY, Barabino GA (2018): Changes in phenotype and differentiation potential of human mesenchymal stem cells aging in vitro. Stem Cell Res. Ther. 9, 131 https://doi.org/10.1186/s13287-018-0876-3

Zhang Y, Khan D, Delling J, Tobiasch E (2012): Mechanisms underlying the osteo- and adipo-differentiation of human mesenchymal stem cells. Sci. World J. 2012, 793823

Received: May 25, 2021

Final version accepted: June 30, 2021 